\title{
Propargylglycine as a Fungal Inhibitor: Effect on Sulphur Amino Acid Metabolism
}

\author{
By MAŁGORZATA PIOTROWSKA* AND ANDRZEJ PASZEWSKI \\ Institute of Biochemistry and Biophysics, Polish Academy of Sciences, 36 Rakowiecka, \\ 02-532 Warszawa, Poland
}

(Received 18 March 1986; revised 19 May 1986)

\begin{abstract}
The effect of propargylglycine (PPG) on four fungal species was studied. $\gamma$-Cystathionase was the major target of the antibiotic, as in mammalian but not in bacterial cells. Highly PPGsensitive $\gamma$-cystathionase was found in Aspergillus nidulans and Neurospora crassa, less sensitive in Saccharomyces cerevisiae and insensitive in Cephalosporium acremonium. The effects of $\gamma$ cystathionase inhibition on growth depend on the role this enzyme plays in cysteine synthesis. Inhibition by PPG was reversed by cysteine, and also by other amino acids at high concentrations. The results of transport assays of wild-type strains and PPG-resistant mutants indicated that propargylglycine was taken up by amino acid permeases in $A$. nidulans and $S$. cerevisiae.
\end{abstract}

\section{INTRODUCTION}

L-Propargylglycine (2-amino-4-pentynoate, PPG), an antibiotic produced by Streptomyces sp. (Scannel et al., 1971) causes growth inhibition of several bacteria, which can be reversed by addition of methionine to the growth medium. It is presumed that the administration of PPG leads to methionine requirement. Inactivation studies have indicated that cystathionine $\gamma$ synthase (see Fig. 1) is the major, if not sole, target in the bacterial methionine biosynthetic pathway (Marcotte \& Walsh, 1975; Johnston et al., 1979).

Effects of PPG in mammals have been studied both in vivo and in vitro. In rats it was found, with living organisms as well as with hepatocyte cells, that PPG interferes with cystathionine metabolism. If injected into rats it caused cystathioninuria and intracellular accumulation of cystathionine and several of its derivatives. The terminal enzyme of the cystathionine pathway, $\gamma$-cystathionase, is irreversibly inhibited by a so-called 'suicidal' inactivation (Abeles \& Walsh, 1973; Beatty \& Reed, 1980). The actual inactivator is generated enzymically at the active site the enzyme catalyses the rearrangement of the acetylenic inhibitor to an allene, which reacts with the enzyme active site, forming a covalent linkage (Washtien \& Abeles, 1977). Some other enzymes are also described as being affected by PPG, although to a lesser extent: e.g. alanine aminotransferase (Burnett et al., 1980) and aspartate aminotransferase from pig heart (Tanase \& Morino, 1976).

In fungi, apart from an early observation that synthetic PPG inhibits the growth of Saccharomyces cerevisiae (Gershon et al., 1949), no information about its effects is available. It was of interest to establish how PPG operates in fungi, as it could eventually be a useful tool in studies of sulphur amino acid metabolism.

\section{METHODS}

Strains. The following strains of Aspergillus nidulans from our collection were used: cys $A 1$ nicA2 yA1, lacking serine transacetylase; cys $B 1$ pyro $A 4$ y $A 1$ and $c y s C l$ chol7 $y A l$, impaired in cysteine synthesis from $O$-acetylserine; cysBl cysCl chol7; cysBl cysDl pyroA4 (cysD is impaired in homocysteine synthase: Paszewski \& Grabski,

Abbreviation: PPG, propargylglycine. 


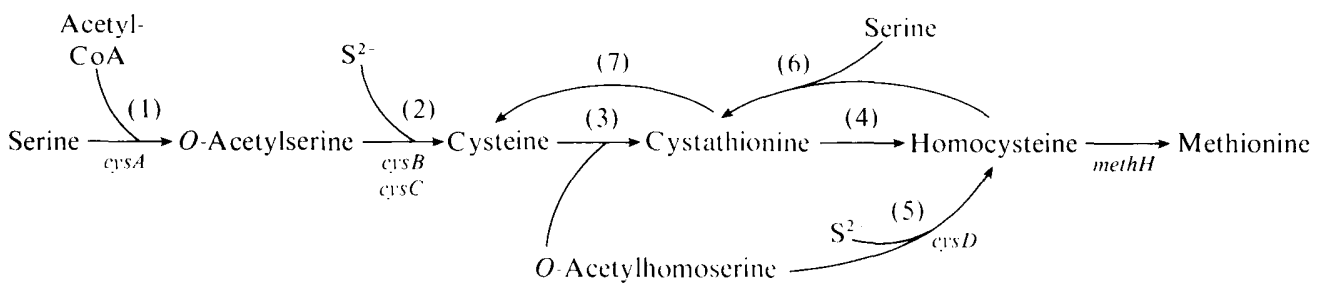

Fig. 1. An outline of sulphur amino acid metabolism in fungi. Enzymes: (1) serine transacetylase, (2) cysteine synthase, (3) cystathionine $\gamma$-synthase, (4) $\beta$-cystathionase, (5) homocysteine synthase, (6) cystathionine $\beta$-synthase, (7) $\gamma$-cystathionase.

1975); and methH pyroA4 yAl, blocked in the last step of methionine biosynthesis. pyroA4 yAl was used as the reference wild-type (WT) strain. Saccharomyces cerevisiae A12-1c (MAT $\alpha$ adel) was used as a standard wild type. Neurospora crassa was 74-OR23-1 A. Both were obtained from Dr A. Kruszewska, Institute of Biochemistry and Biophysics, Warsaw, Poland. A wild-type Cephalosporium acremonium strain II-WT was obtained from the Biotechnology Research Development Centre, Warsaw, Poland.

Media, growth conditions and extract preparations. The minimal medium described by Paszewski \& Grabski (1974) was used for $A$. nidulans strains, the minimal medium of Vogel (1964) for $N$. crassa, the minimal medium described by Nüesh et al. (1973) for $C$. acremonium and GO minimal medium as described by Świetlińska $e t$ al. (1978) for $S$. cerevisiae. These media were supplemented according to nutritional requirements. All strains were grown at $30^{\circ} \mathrm{C}$ on a rotary shaker (150 r.p.m.) and harvested in the exponential phase of growth. Cell extracts were prepared as described by Paszewski et al. (1984), except for yeast, where cells were disrupted in a Braun homogenizer.

Enzyme assays. Cystathionine $\beta$-synthase (EC 4.2.1.22) was assayed according to Pieniązek et al. (1973). Homocysteine synthase (EC 4.2.99.10) was assayed using the reaction mixture described by Paszewski \& Grabski (1973); homocysteine formed was estimated by the method of Kredich \& Tomkins (1966). The activities of $\beta$-cystathionase (EC 4.4.1.8) and $\gamma$-cystathionase (EC 4.4.1.1) were determined as described by Paszewski \& Grabski (1974). The procedure for determination of amino acid transport was essentially the same as that of Piotrowska et al. (1976). The incubation mixture contained $125-250 \mu \mathrm{M}$-radioactive amino acid $[0 \cdot 2 \mu \mathrm{Ci}(7 \cdot 4 \mathrm{kBq})$ per assay] and uptake was followed for $3 \mathrm{~min}$ for $A$. nidulans and $2 \mathrm{~min}$ for yeasts. Protein was estimated by the method of Bradford (1976).

Determination of pools of ${ }^{35} \mathrm{~S}$-labelled amino acids. A. nidulans strains were grown for $18 \mathrm{~h}$ under standard conditions, then $2 \mathrm{mM}-\mathrm{Na}_{2}{ }^{35} \mathrm{SO}_{4}\left(1-1.5 \times 10^{6}\right.$ c.p.m. $\left.\mu \mathrm{mol}^{-1}\right)$ was added to two parallel cultures, and simultaneously PPG to $10 \mu \mathrm{M}$ final concentration to one of them. After $6 \mathrm{~h}$, cultures were harvested. S. cerevisiae was grown in the presence of $2 \mathrm{mM}-\mathrm{Na}_{2}{ }^{35} \mathrm{SO}_{4}\left(0 \cdot 1-0.2 \times 10^{6} \mathrm{c}\right.$.p.m. mol $\left.{ }^{-1}\right)$; PPG $(75 \mu \mathrm{M})$ was added to one of the two identical cultures. Cultures were harvested in the late-exponential phase. The ${ }^{35} \mathrm{~S}$-labelled amino acid content of the cells was determined as described by Paszewski et al. (1984).

Reagents. $O$-Acetylserine and $O$-acetylhomoserine were synthesized according to Wiebers \& Garner (1967). Other amino acids were from Sigma. PPG was the DL-product, from Sigma. Radioactive amino acids were the $\mathrm{L}_{-}$ $\mathrm{U} \cdot{ }^{14} \mathrm{C}$ forms from UVVVR-Praha; $\left[{ }^{35} \mathrm{~S}\right]$ methionine was from Amersham. $\mathrm{Na}_{2}{ }^{35} \mathrm{SO}_{4}$ was from the Institute of Nuclear Research, Świerk, Poland.

\section{RESULTS}

$A$. nidulans strains $c y s B$, cys $C$ and $\operatorname{cys} A$, impaired in the main pathway of cysteine synthesis, were highly sensitive to PPG, as compared to the wild-type. Complete growth inhibition was observed with $1 \mu \mathrm{M}-\mathrm{PPG}$, whereas the growth of the wild-type was only partly inhibited by $1 \mathrm{mM}$-PPG (Table 1). When the mycelial mass increase of strain cys $B$ in the presence of PPG was determined, no increase was observed during the first $6 \mathrm{~h}$ and only a $10 \%$ increase after $24 \mathrm{~h}$.

$A$. nidulans mutants $c y s B, \operatorname{cys} C$ and $\operatorname{cys} A$ are prototrophs, due to the functioning of the alternative pathway of cysteine synthesis involving homocysteine synthase, cystathionine $\beta$ synthase and $\gamma$-cystathionase (Paszewski \& Grabski, 1975). Their higher sensitivity to PPG suggested that this pathway is blocked by the antibiotic. By analogy with mammalian systems, $\gamma-$ cystathionase seemed the most likely target. In experiments in vitro, $A$. nidulans $\gamma$-cystathionase was inhibited to the following extent by different PPG concentrations: $1 \mu \mathrm{M}, 20 \% ; 2 \mu \mathrm{M}, 38 \%$; 
Table 1. Effect of PPG on the growth of wild-type and cys A, cysB and cysC mutants of A. nidulans

The diameter of colonies grown for $48 \mathrm{~h}$ was measured: - , no growth; + to ++++ , increasing amounts of growth.

\begin{tabular}{|c|c|c|c|c|c|c|c|c|c|}
\hline \multirow[b]{2}{*}{ Strain } & \multicolumn{9}{|c|}{ Growth in the presence of PPG at the concn $(\mu \mathrm{M})$ indicated } \\
\hline & 1000 & 100 & 10 & 1 & 0.5 & $0 \cdot 1$ & 0.01 & 0.001 & 0 \\
\hline $\operatorname{cys} A$ & - & - & - & - & $+1-$ & + & $++t$ & +++ & +++ \\
\hline cysB & - & - & - & - & - & $+1-$ & + & ++ & +++ \\
\hline $\operatorname{cys} C$ & - & - & - & - & - & $+1-$ & + & ++ & +++ \\
\hline WT & ++ & ++++ & ++++ & ++++ & ++++ & $+++t$ & $+t+t$ & $+t+t$ & $+++t$ \\
\hline
\end{tabular}

Table 2. Effect of PPG on $\gamma$-cystathionase activity and generation time in $S$. cerevisiae

In experiments A, $\gamma$-cystathionase activity was measured in cells grown to mid-exponential phase in GO supplemented as indicated. In experiments B, PPG and methionine were added for $1 \mathrm{~h}$ to cultures grown in GO to exponential phase. Generation time was established in separate experiments. Values are means from at least three determinations.

\begin{tabular}{|c|c|c|c|c|}
\hline \multirow{2}{*}{$\begin{array}{l}\text { Expt } \\
\text { type }\end{array}$} & \multicolumn{2}{|c|}{$\begin{array}{c}\text { Medium } \\
\text { supplementation }\end{array}$} & \multirow{2}{*}{$\begin{array}{c}\gamma \text {-Cystathionase } \\
{[\text { nmol min }-1} \\
\left.(\mathrm{mg} \text { protein })^{-1}\right]\end{array}$} & \multirow{2}{*}{$\begin{array}{l}\text { Generation } \\
\text { time } \\
\text { (h) }\end{array}$} \\
\hline & PPG & Methionine & & \\
\hline A & - & - & 5.7 & 1.75 \\
\hline A & $50 \mu \mathrm{M}$ & - & $4 \cdot 2$ & $2 \cdot 75$ \\
\hline B & $100 \mu \mathrm{M}$ & - & $0-0.3$ & 6.0 \\
\hline B & $.500 \mu \mathrm{M}$ & - & $0-0.2$ & $6 \cdot 0$ \\
\hline B & $1 \mathrm{mM}$ & - & 0 & $\infty$ \\
\hline$A$ & $500 \mu \mathrm{M}$ & $10 \mathrm{~mm}$ & $1 \cdot 1$ & $2 \cdot 33$ \\
\hline B & $1 \mathrm{mM}$ & $10 \mathrm{mM}$ & 0.2 & $5-6$ \\
\hline
\end{tabular}

$5 \mu \mathrm{M}, 65 \% ; 10 \mu \mathrm{M}, 68 \% ; 20 \mu \mathrm{M}, 86 \% ; 200 \mu \mathrm{M}, 100 \%$ (means from three experiments). No inhibition of cystathionine $\beta$-synthase or homocysteine synthase was observed at PPG concentrations up to $200 \mu \mathrm{M}$ (the latter enzyme was inhibited about $50 \%$ by $2 \mathrm{mM}-\mathrm{PPG}$ ). Since these two enzymes are not subject to PPG inhibition, we conclude that blockage of $\gamma$ cystathionase is the main effect of this antibiotic responsible for the growth inhibition of the cys mutants of $A$. nidulans.

Addition of PPG to cultures of $A$. nidulans resulted in a decrease of $\gamma$-cystathionase activity. Total inhibition was observed in extracts from mycelia collected $45 \mathrm{~min}$ after administration of $1 \mu \mathrm{M}-\mathrm{PPG}$.

$S$. cerevisiae was more sensitive to PPG than the $A$. nidulans wild-type strain but more resistant than the cys strains. At $100 \mu \mathrm{M}-\mathrm{PPG}$ the generation time increased from $1.75 \mathrm{~h}$ to about $6 \mathrm{~h}$ (Table 2). Yeast $\gamma$-cystathionase tested in vitro was inhibited by PPG: $100 \mu \mathrm{M}$ caused about $40 \%$ inhibition. Since no $S$. cerevisiae mutants corresponding to the $A$. nidulans cys $B$ and $c y s C$ strains are available, it is difficult to establish whether $\gamma$-cystathionase activity is indispensable for this organism. The data in Table 2 show a fairly good correlation between the level of $\gamma$ cystathionase and prolongation of the generation time. This suggests that $\gamma$-cystathionase inhibition may be the cause of PPG toxicity, but we can not exclude the possibility that some target other than $\gamma$-cystathionase is responsible for the observed effect.

In $N$. crassa growth inhibition by PPG started at $0.5 \mathrm{mM}-\mathrm{PPG}$, while the growth of $C$. acremonium was not affected even by 2 mM-PPG. $N$. crassa $\gamma$-cystathionase was inhibited $50 \%$ in vitro by $5 \mu \mathrm{M}$-PPG. No activity of the enzyme was found in mycelium grown in the presence of $1 \mu \mathrm{M}$-PPG. $N$. crassa therefore appeared to resemble $A$. nidulans with respect to PPG toxicity. $\gamma$ Cystathionase from $C$. acremonium was quite resistant to PPG: less than $50 \%$ inhibition in vitro was observed with $1 \mathrm{mM}-\mathrm{PPG}$. 
Table 3. Accumulation of ${ }^{35}$ S-labelled amino acids in A. nidulans and S. cerevisiae strains in the presence of $P P G$

Values are given as nmol $(\mathrm{g} \text { dry } w \mathrm{t})^{-1}$ and are means of four independent experiments \pm SEM.

$\begin{array}{lcccccc}\text { Organism } & \text { Strain } & \text { PPG } & \text { Cysteine } & \text { Homocysteine } & \text { Glutathione } & \text { Cystathionine } \\ \text { A. nidulans } & \text { WT } & - & 99 \pm 26 & 148 \pm 42 & 1173 \pm 435 & 350 \pm 112 \\ & & 10 \mu \mathrm{M} & 127 \pm 49 & 171 \pm 127 & 971 \pm 350 & 386 \pm 142 \\ & c y s B & - & 239 \pm 76 & 166 \pm 75 & 509 \pm 52 & 819 \pm 191 \\ & & 10 \mu \mathrm{M} & 41 \pm 17 & 78 \pm 24 & 51 \pm 28 & 250 \pm 59 \\ S . \text { cerevisiae } & & - & 68 \pm 12 & 71 \pm 29 & 1666 \pm 400 & 139 \pm 67 \\ & & 75 \mu \mathrm{M} & 105 \pm 11 & 218 \pm 73 & 2055 \pm 538 & 458 \pm 267\end{array}$

Table 4. Reversal of PPG-induced growth inhibition of $A$. nidulans by amino acids

\begin{tabular}{cl} 
PPG & \multicolumn{1}{|c}{$\begin{array}{c}\text { Medium } \\
\text { supplementation acid }\end{array}$} \\
- & Methionine $100 \mu \mathrm{M}$ \\
- & $\quad$ Methionine $100 \mu \mathrm{M}$ \\
$1 \mu \mathrm{M}$ & Methionine $1 \mathrm{mM}$ \\
$1 \mu \mathrm{M}$ & Methionine $10 \mathrm{mM}$ \\
$1 \mu \mathrm{M}$ & Cysteine $100 \mu \mathrm{M}$ \\
$1 \mu \mathrm{M}$ & Cysteine $100 \mu \mathrm{M}$ \\
- & Cysteine $500 \mu \mathrm{M}$ \\
$1 \mu \mathrm{M}$ & Serine $10 \mathrm{mM}$ \\
$1 \mu \mathrm{M}$ & Serine $100 \mathrm{mM}$ \\
$1 \mu \mathrm{M}$ &
\end{tabular}

\begin{tabular}{cccc}
\multicolumn{4}{c}{ Growth* of strain: } \\
\hline WT & methH & cysB cys $D$ & cysB \\
++++ & $+1-$ & - & +++ \\
++++ & +++ & ++ & +++ \\
++++ & $+1-$ & - & - \\
++++ & +++ & - & - \\
++++ & +++ & + & + \\
++++ & +++ & +++ & +++ \\
++++ & $+1-$ & ++ & +++ \\
++++ & $+1-$ & ++ & +++ \\
++++ & $+1-$ & +++ & +++ \\
++++ & $+1-$ & - & - \\
++++ & $+1-$ & - & ++
\end{tabular}

* Measured as described for Table 1.

\section{Effect of propargylglycine upon sulphur amino acid pools}

In the $A$. nidulans wild-type strain the presence of $10 \mu \mathrm{M}-\mathrm{PPG}$ in the growth medium had no effect on the pools of sulphur amino acids (Table 3 ). This observation strongly supports the conclusion that $\gamma$-cystathionase does not play a significant physiological role in this strain. On the other hand, in the cysB mutant, in which cysteine synthesis depends on $\gamma$-cystathionase activity, a considerable decrease of the sulphur amino acid pools was observed. It was most pronounced for glutathione. Cysteine was also diminished, whereas the cystathionine pool, although low, was relatively high in comparison to other sulphur amino acids. It should be noted that this small accumulation of these amino acids took place during growth inhibition.

With S. cerevisiae the presence of $75 \mu \mathrm{M}-\mathrm{PPG}$ in liquid culture resulted in some increase of the cystathionine and homocysteine pools (Table 3). However, cysteine and glutathione were not diminished, so it is not clear why PPG at this concentration slowed the growth rate. One possibility is that the growth rate is adjusted to keep the cysteine and glutathione pools relatively constant.

\section{Reversal of PPG-induced growth inhibition by amino acids}

Reversal of the PPG-induced growth inhibition of $A$. nidulans by several amino acids was observed (Table 4). Cysteine auxotrophy should arise from the combination of a cys $B$ block with $\gamma$-cystathionase inhibition by $1 \mu \mathrm{M}$-PPG. Indeed, cysteine at a concentration $(100 \mu \mathrm{M})$ sufficient to supply the auxotrophic requirement of the cysB cysD strain restored the growth of $c y s B$. Methionine reversed the inhibition, but, as may be seen from tests with auxotrophic mutants meth $H$ and cysB cys $D$, only at a much higher concentration than that needed for supplementing 


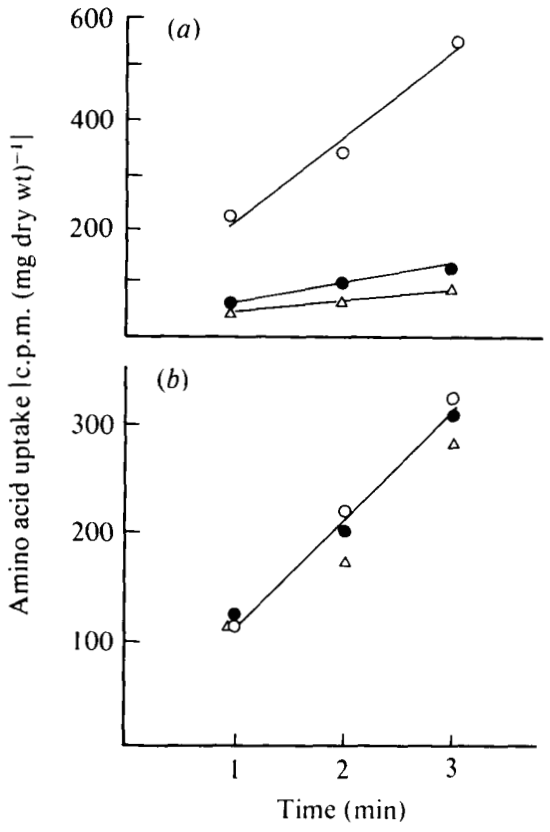

Fig. 2

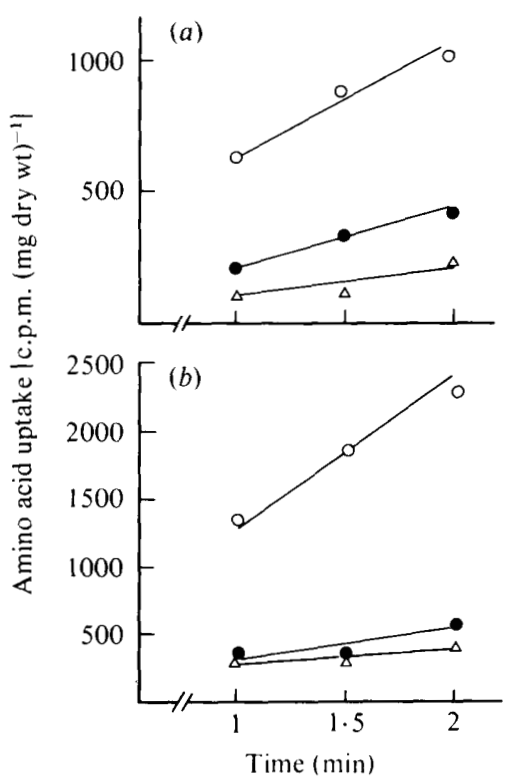

Fig. 3

Fig. 2. Transport of $(a) \mathrm{L}-\left[{ }^{14} \mathrm{C}\right]$ leucine and $(b) \mathrm{L}-\left[{ }^{14} \mathrm{C}\right]$ arginine in the presence and absence of $\mathrm{PPG}$ in strain cys $B$ cys $C$ of $A$. nidulans and a PPG-resistant mutant of this strain. $O, \operatorname{cys} B$ cys $C ; O$, cys $B$ cys $C$, $1 \mathrm{mM}-\mathrm{PPG}$ present; $\triangle$, PPG-resistant mutant. The results are from one representative experiment.

Fig. 3. Transport of $(a) \mathrm{L}-\left[{ }^{35} \mathrm{~S}\right]$ methionine and $(b) \mathrm{L}-\left[{ }^{14} \mathrm{C}\right]$ leucine in the presence and absence of PPG in the wild-type strain of $S$. cerevisiae and a PPG-resistant mutant of this strain. $O$, Wild-type; wild type, $1 \mathrm{mM}-\mathrm{PPG}$ present; $\triangle$, PPG-resistant mutant. The results are from one representative experiment.

auxotrophy. Besides methionine, other amino acids restored growth when supplied at high concentrations. The same phenomenon of protection by amino acids at high concentrations was observed with regard to the effect of $1 \mathrm{mM}-\mathrm{PPG}$ on the wild-type (now shown).

When 10 mM-methionine was added to liquid cultures of wild-type $A$. nidulans together with $1 \mu \mathrm{M}-\mathrm{PPG}$, almost no inhibition of $\gamma$-cystathionase was observed.

In S. cerevisiae, methionine added to the medium together with PPG restored both growth and $\gamma$-cystathionase activity. The effect depended on the ratio of methionine to inhibitor (Table 2). About $90 \%$ of normal $\gamma$-cystathionase activity was found in cells grown in the presence of $100 \mu \mathrm{M}$-PPG plus either $10 \mathrm{mM}$-cysteine or $50 \mathrm{mM}$-leucine, whereas $50 \mathrm{~mm}$-proline had no effect.

We have already suggested that, in the cys $B$ mutant of $A$. nidulans, PPG-induced inhibition of growth is the result of auxotrophy since it can be reversed by cysteine at low concentration. In $S$. cerevisiae, a higher concentration of cysteine is required to reverse inhibition, and in both organisms a high concentration of metabolically unrelated amino acids may reverse inhibition. These observations imply the existence of a second mechanism for the relief of inhibition, possibly at the level of transport.

\section{Interference of $P P G$ with amino acid transport: mutants resistant to $P P G$}

In $A$. nidulans grown on minimal medium, neutral amino acids, including sulphur-containing ones, are taken up by a so-called neutral permease; a separate permease transports basic amino acids like arginine and lysine (Piotrowska et al., 1976). In the experiment shown in Fig. 2, the direct effect of PPG on the uptake of a neutral amino acid (leucine) and a basic one (arginine) was studied. PPG at five times the concentration of leucine inhibited its uptake. In contrast, 
PPG did not restrict the uptake of arginine. Thus PPG interferes with the uptake of neutral amino acids.

From a cys $B$ cys $C$ double mutant of $A$. nidulans sensitive to $1 \mu \mathrm{M}-\mathrm{PPG}$, several PPG-resistant mutants were isolated following UV mutagenesis. When two of them were tested for amino acid transport, they were found to be impaired in the uptake of two neutral amino acids: leucine and phenylalanine. No difference from the wild-type was found for the rate of transport of arginine (Fig. 2). These mutants are likely to be impaired in the neutral amino acid permease, and their simultaneous resistance to the inhibition of PPG supports the conclusion that PPG enters the cell by the neutral amino acid transport system.

In $S$. cerevisiae most of the amino acids (basic and neutral, but not proline) are transported by a high-velocity system, the so-called general amino acid permease (Gap) (Grenson et al., 1970). The observed pattern of protection could suggest transport of PPG via Gap. In some yeast strains Gap is inactive in the presence of ammonia. Gap is responsible for transport of D-amino acids, highly toxic to yeast, which offers a simple test for Gap sensitivity to ammonia (Rytka, 1975). Inhibition of our strain by D-serine and D-histidine was examined on GO medium containing ammonia and on a medium with proline as sole nitrogen source. The strain was sensitive to D-amino acids on the proline medium only, and this thus of the ammonia-sensitive type. The next test was performed with citrulline, which according to Grenson et al. (1970) enters the cells only via Gap. When citrulline at high concentrations (10 $\mathrm{mm}$ and above) was included together with $100 \mu \mathrm{M}-\mathrm{PPG}$ in the medium, no protection against PPG toxicity was observed whether proline or ammonia was used as nitrogen source. Hence Gap should probably be excluded as a transport system for PPG.

Besides Gap, several (at least 10) amino acid transport systems have been described in $S$. cerevisiae, each specific for only one or a small number of amino acids (Grenson et al., as cited by Rytka, 1975). We checked, on GO medium, whether PPG interfered with the transport of methionine, leucine and arginine, each of which is transported by a separate permease (Fig. 3). The initial rates of transport of both leucine and methionine were markedly decreased by $1 \mathrm{mM}$ PPG. Transport of arginine was not affected even by 5 mM-PPG (now shown).

Mutants of $S$. cerevisiae resistant to PPG were obtained after UV mutagenesis on GO supplemented with $250 \mu \mathrm{M}$-PPG. Activity of $\gamma$-cystathionase was checked in several of them and found to be unchanged. Two such mutants were chosen arbitrarily and transport of amino acids was assayed. They both displayed lowered transport rates for leucine and methionine (Fig. 3), but the normal rate for arginine.

We cannot therefore attribute PPG transport with certainty to any particular yeast amino acid permease, but the results of the uptake experiments, taken together, point to transport as the level of PPG-amino acid interference.

\section{DISCUSSION}

In bacteria, PPG inhibits cystathionine $\gamma$-synthase. An $A$. nidulans mutant blocked in this step of methionine synthesis is an auxotroph (Paszewski \& Grabski, 1975). The fact that in the wildtype administration of $1 \mu \mathrm{M}-\mathrm{PPG}$ does not result in methionine auxotrophy excludes cystathionine $\gamma$-synthase as being blocked by $1 \mu \mathrm{M}$-PPG. On the other hand, $\gamma$-cystathionase is completely inhibited at this concentration of PPG. Thus the mode of action of PPG in $A$. nidulans resembles that found in mammals, rather than that in bacteria. At higher concentrations of PPG (1 mM) some inhibition of the growth of wild-type A. nidulans was observed, but no conclusion can be drawn concerning its nature. We suspect that, at this concentration, several nonspecific effects, as described in the literature, may be responsible for growth inhibition. In $A$. nidulans we did not observe an inverse correlation between the glutathione and cystathionine pools as found in mammalian cells (Shinozuka et al., 1982), where $\gamma$-cystathionase inhibition by PPG administered in vivo results in parallel cystathionine accumulation and glutathione decrease. These results support earlier findings that the homocysteine to cysteine pathway does not operate in the wild-type of $A$. nidulans grown on sulphate as a sulphur source, in contrast to the $c y s B$ strain impaired in the main pathway of 
cysteine synthesis. PPG-induced growth inhibition, presumed cysteine auxotrophy and the drastic decrease of the sulphur amino acid pool in the $c y s B$ strain indicate that the functioning of this pathway is indispensable for the latter strain.

The role of $\gamma$-cystathionase in $S$. cerevisiae is not clear. No mutants corresponding to $A$. nidulans cys $B$ and cys $C$ strains are known in this organism, and it is thus more difficult to say whether the effect of PPG on $\gamma$-cystathionase is mainly responsible for growth inhibition. No $\gamma$ cystathionase-less mutant was, until recently, known in yeasts. Ono et al. (1984) described a mutant with lowered $\gamma$-cystathionase activity. It accumulates cystathionine, which suggests that at least some part of cysteine is synthesized from cystathionine. This mutant is a prototroph, and the authors do not report any decrease in its growth rate, which in turn suggests that $\gamma$ cystathionase is not essential for $S$. cerevisiae.

Our data obtained with four fungal species indicate that $\gamma$-cystathionase sensitivity to PPG may differ among various fungi. Highly sensitive ( $A$. nidulans and $N$. crassa) and highly resistant (C. acremonium) enzymes were found. In the case of a fungus with PPG-sensitive $\gamma$ cystathionase, the use of the antibiotic may give insight into the physiological role of this enzyme.

An important finding of this investigation is that, in fungi, PPG is transported into the cells by amino acid permeases, which has several implications for the use of this antibiotic in these organisms. It is worth noting that the interference of PPG with amino acid transport in mammalian cells has been ruled out (Beatty \& Reed, 1980).

This work was supported by the Polish Academy of Sciences within the projects 09.7 and CPBR 3.13.

\section{REFERENCES}

Abeles, R. H. \& Walsh, C. (1973). Acetylenic enzyme inactivation of $\gamma$-cystathionase, in vitro and in vivo, by propargylglycine, Journal of the American Chemical Society 95, 6124-6125.

Beatty, P. W. \& REed, D. J. (1980). Involvement of the cystathionine pathway in the biosynthesis of glutathione by isolated rat hepatocytes. Archives of Biochemistry and Biophysics 204, 80-87.

BRADFORD, M. M. (1976). A rapid and sensitive method for the quantitation of microgram quantities of protein utilising the principle of protein-dye binding. Analytical Biochemistry 18, 248-254.

Burnett, G., Marcotte, P. \& Walsh, C. (1980). Mechanism-based inactivation of pig-heart alanine transaminase by L-propargylglycine. Journal of Biological Chemistry 255, 3487-3491.

Gershon, H., MeeK, J. S. \& Dittmer, K. (1949). Propargylglycine: an acetylenic amino acid antagonist. Journal of the American Chemical Society 71, 3573-3574.

Grenson, M., Hou, C. \& Crabeel, M. (1970). Multiplicity of the amino acid permeases in Saccharomyces cerevisiae. IV. Evidence for a general amino acid permease. Journal of Bacteriology 103, 770-777.

Johnston, M., Jankowski, D., Marcotte, P., TanAKa, H., Esaki, N., Soda, K. \& Walsh, C. (1979). Suicide inactivation of bacterial cystathionine $\gamma$ synthase and methionine lyase during processing of L-propargylglycine. Biochemistry 18, 4690-4701.

KREDiCH, N. M. \& TomkINS, G. N. (1966). The enzymic synthesis of L-cysteine in $E$. coli and $S$. typhimurium. Journal of Biological Chemistry 241, 4965-4995.

MarcotTe, P. \& Walsh, C. (1975). Active-site directed inactivation of cystathionine $\gamma$-synthase and glutamic pyruvic transaminase by propargylglycine.
Biochemical and Biophysical Research Communications 62, 677-682.

Nüesh, J., Treichler, H. J. \& Liersh, M. (1973). The biosynthesis of cephalosporin. In Genetics of Industrial Microorganisms, Ascomycetes and Fungi, pp. 309-344. Edited by Z. Vanek, Z. Hostalek \& J. Gudlin. New York: American Elsevier.

Ono, B., Suruga, T., Yamamoto, M., Mutata, K., Kimuta, A., Shinoda, S. \& OHMORI, S. (1984). Cystathionine accumulation in Saccharomyces cerevisiae. Journal of Bacteriology 158, 860-865.

Paszewski, A. \& Grabski, J. (1973). Studies on $\gamma$ cystathionase and $O$-acetylhomoserine sulfhydrylase as the enzymes of alternative biosynthetic pathway in Aspergillus nidulans. Acta biochimica polonica 20, 159-168.

Paszewski, A. \& Grabski, J. (1974). Regulation of Samino acid biosynthesis in Aspergillus nidulans: role of cysteine and/or homocysteine as regulatory effector. Molecular and General Genetics 132, 307-320.

PASZEWSKI, A. \& GRABSKI, J. (1975). Enzymatic lesions in methionine mutants of Aspergillus nidulans: role and regulation of an alternative pathway for cysteine and methionine synthesis. Journal of Bacteriology 124, 893-904.

Paszewski, A., Prażo, W., Nadolska, J. \& ReGULSKI, M. (1984). Mutations affecting the sulphur assimilation pathway in Aspergillus nidulans: their effect on sulphur amino acid metabolism. Journal of General Microbiology 130, 1113-1121.

Pieniążek, N. J., Sţ̧Pié́, P. P. \& Paszewski, A. (1973). An Aspergillus nidulans mutant lacking cystathionine $\beta$-synthase : identity of L-serine sulfhydrylase with cystathionine $\beta$-synthase and its distinctness from acetyl L-serine sulfhydrylase. Biochimica et biophysica acta 297, 34-47. 
Piotrowska, M., Stęrień, P. P., Bartnik, E. \& ZAKRZEWSKA, E. (1976). Basic and neutral amino acid transport in Aspergillus nidulans. Journal of General Microbiology 92, 89-96.

RYTKA, J. (1975). Positive selection of general amino acid permease mutants in Saccharomyces cerevisiae. Journal of Bacteriology 121, 562-570.

Scannel, D. L., Preuss, D. L., Demny, T. C., Weiss, E., Williams, A. \& Stempel, A. (1971). Antimetabolites produced by microorganisms: 1,2-amino-4pentynoic acid. Journal of Antibiotics 24, 239.

ShinozuKa, S., Tanase, S. \& Morino, Y. (1982). Metabolic consequences of affinity labelling of cystathionase and alanine aminotransferase by propargylglycine in vivo. European Journal of Biochemistry 124, 377-382.

Świelínska, Z., ZaborowsKa, D., Haladus, E. \& ŻUK, J. (1978). Study on liquid-holding recovery in
DEB-inactivated rad3 mutant of Saccharomyces cerevisiae. Molecular and General Genetics 166, 97102.

TANASE, S. \& MORINO, Y. (1976). Irreversible inactivation of aspartate aminotransferase during transamination with L-propargylglycine. Biochemical and Biophysical Research Communications 68, 1301-1308.

VoGEL, H. J. (1964). Distribution of lysine pathways among fungi: evolutionary implications. American Naturalist 98, 435-439.

Washtien, W. \& Abeles, R. H. (1977). Mechanism of inactivation of $\gamma$-cystathionase by the acetylenic substrate analogue propargylglycine. Biochemistry 16, 2485-2491.

WIEBers, J. L. \& Garner, Y. (1967). Acyl derivatives of homoserine as substrate for homocysteine synthesis in Neurospora crassa, yeast and Escherichia coli. Journal of Biological Chemistry 242, 5644-5649. 